Article

\title{
Determining the Efficacy, Safety and Suitability of Disinfectants to Prevent Emerging Infectious Disease Transmission
}

\author{
Daniele Lantagne ${ }^{1, *}$, Marlene Wolfe ${ }^{1}$, Karin Gallandat ${ }^{1}$ and Melissa Opryszko ${ }^{2}$ \\ 1 School of Engineering, Tufts University, Medford, MA 02155, USA; marlene.wolfe@tufts.edu (M.W.); \\ karin.gallandat@tufts.edu (K.G.) \\ 2 Office of Foreign Disaster Assistance, United States Agency for International Development, \\ Washington, DC 22202, USA; mopryszko@ofda.gov \\ * Correspondence: daniele.lantagne@tufts.edu; Tel.: +1-617-549-1586
}

Received: 27 August 2018; Accepted: 2 October 2018; Published: 9 October 2018

\begin{abstract}
The scale of the 2014-2017 West African Ebola Virus Disease outbreak overwhelmed the international response capacity. This has led to inconsistencies in international guidance documents, particularly around chlorine disinfection of surfaces and hands to prevent transmission. To provide evidence for the disinfection recommendations, three research strands were conducted: (1) impacts of chlorine chemistry; (2) efficacy of surface cleaning recommendations; and (3) safety and efficacy of handwashing recommendations. Strand 1 research found that the compound chemistry of the chlorine source has an impact on the chlorine solution shelf-life ( $<1$ day-30 days), with testing of chlorine solutions recommended to ensure accuracy. Strand 2 research found that surface cleaning with $0.5 \%$ chlorine solutions with a 15-min exposure time is efficacious in reducing transmission risk. Strand 3 research found that community handwashing with chlorine solutions is as safe and efficacious as handwashing with soap and water or sanitizer, which offers a benefit of reducing pathogens in the rinsing water. Using calcium hypochlorite as the chlorine source compound provided a particularly good performance in chemistry and handwashing studies. The research was successful at providing information to align with the inconsistent international guidelines. Further research is needed to proactively establish the efficacy, safety and suitability of disinfection for the seven viral pathogens that are considered likely to cause severe outbreaks with few/no medical countermeasures.
\end{abstract}

Keywords: disinfectants; efficacy; emerging infectious diseases; feasibility; safety

\section{Introduction}

During the 2014-2017 West African Ebola Virus Disease (EVD) outbreak, 493 of 500 healthcare providers (99\%) and 550 of 550 patients (100\%) who were surveyed reported that their body had been deliberately sprayed with $0.5 \%$ chlorine solution [1]. This is a denigrating, non-evidence based disinfection intervention that damages eyes, skin and lungs. This spraying occurred due to fear and lack of information, which highlights the need for improved recommendations for appropriate disinfection procedures in EVD response.

Disinfectants are critical for cleaning living and non-living surfaces and preventing the transmission of infectious diseases. The Centers for Disease Control and Prevention's (CDC) framework for preventing infectious disease transmission includes three elements: (1) public health fundamentals, including surveillance, laboratory detection and epidemiologic investigation; (2) high-impact interventions, including new vaccines, strategies and tools for infection control and treatment and other interventions to reduce zoonotic transmission; and (3) policies to prevent, detect and control infectious diseases [2]. 
One key strategy for infection control is cleaning, disinfection and sterilization [3]. According to CDC, cleaning is the "removal of visible soil (e.g., organic and inorganic material) from objects and surfaces and normally is accomplished manually or mechanically using water with detergents or enzymatic products"; disinfection "describes a process that eliminates many or all pathogenic microorganisms, except bacterial spores, on inanimate objects"; and sterilization "describes a process that destroys or eliminates all forms of microbial life". Evidence-based recommendations on the preferred methods for cleaning (e.g., towels, soap), disinfecting (e.g., chlorine, quaternary ammonium compounds) and sterilizing (e.g., steam sterilization, liquid peracetic acid) have been largely established for well-resourced healthcare settings. However, there are currently two critical knowledge gaps on disinfection, including: (1) disinfectant efficacy against emerging infectious disease (EID) pathogens; and (2) disinfectant options for low-resource settings. The current EID pathogens (considered to be those that are likely to cause severe outbreaks in the near future and for which few or no medical countermeasures exist) are: Crimean Congo Hemorrhagic Fever, EVD and Marburg, Lassa Fever, MERS and SARS coronavirus diseases and Nipah and Rift Valley Fever [4]. All of these diseases are caused by viral pathogens and all can cause outbreaks in low-resource settings.

Historically, the Doctors Without Borders (Médecins Sans Frontèires, MSF) organization provided medical care in EVD outbreaks in collaboration with national governments. The 2008 MSF Filovirus hemorrhagic fever guideline recommends using $0.05 \%(500 \mathrm{mg} / \mathrm{L})$ chlorine solutions to disinfect living things (people and hands) and $0.5 \%(5,000 \mathrm{mg} / \mathrm{L})$ chlorine solutions to disinfect non-living things (surfaces, personal protective equipment and dead bodies) [5]. However, these recommendations were intended for Ebola Treatment Units (ETU) and there was no evidence provided that supports the recommendations. The scale and size of the West African EVD outbreak overwhelmed international response capacity, which led to: (1) MSF guidelines being widely expanded to community settings; and (2) the World Health Organization (WHO) and CDC also developing disinfection guidelines, based on expert consensus [5-7]. The inconsistencies between these guidance documents led to confusion in the response (Table 1).

Table 1. Inconsistencies in International EVD Chlorine Recommendations.

\begin{tabular}{cccc}
\hline Chlorine Solution Type & MSF [5] & WHO [6] & CDC [7] \\
\hline $\begin{array}{c}\text { Chlorine Solution } \\
\text { Testing }\end{array}$ & Not recommended & Not addressed & Not addressed \\
\hline Surface Cleaning & Apply 0.5\% chlorine for \\
15 min & $\begin{array}{c}\text { Pre-clean, apply 0.5\% } \\
\text { chlorine for 10 min. }\end{array}$ & $\begin{array}{c}\text { For hospitals: pre-clean, apply a } \\
\text { "chemical disinfectant for } \\
\text { non-enveloped viruses". For } \\
\text { households: cover spills, apply 0.5\% } \\
\text { chlorine for 15 min. }\end{array}$ \\
\hline Handwashing & $0.05 \%$ chlorine solution & $\begin{array}{c}\text { Soap, sanitizer, avoid } \\
\text { chlorine solution }\end{array}$ & $\begin{array}{c}\text { Soap, sanitizer, avoid chlorine } \\
\text { solution }\end{array}$ \\
\hline
\end{tabular}

Acronyms: MSF (Médecins Sans Frontèires); WHO (World Health Organization); CDC (Centers for Disease Control and Prevention, HTH (calcium hypochlorite, high-test hypochlorite), NaDCC (sodium dichloroisocyanurate).

At Tufts University, we conducted laboratory, field and policy research to reduce the burden of infectious diseases. Furthermore, we are members of water, sanitation and hygiene emergency response groups. During and after the West African EVD outbreak, we conducted research, funded by the United States Agency for International Development's Office of U.S. Foreign Disaster Assistance (USAID/OFDA), to answer the questions that responders were asking related to the inconsistencies between the MSF, WHO and CDC guidelines, including: (1) impacts of chlorine chemistry on shelf-life and solution testing; (2) efficacy of surface cleaning recommendations; and (3) safety and efficacy of handwashing recommendations. In this communication, we summarize the results of these three 
research streams (which led to eight individual peer-reviewed manuscripts summarized herein) and propose future disinfection research for EID contexts.

\section{Materials and Methods}

\subsection{EVD Research Thread \#1: Chlorine Chemistry Methods}

Chlorine solutions in emergencies are primarily made from the chlorine source compounds of powdered calcium hypochlorite $(\mathrm{HTH})$, granular sodium dichloroisocyanurate $(\mathrm{NaDCC})$ and liquid sodium hypochlorite $(\mathrm{NaOCl})$. $\mathrm{NaOCl}$ solutions can be generated from an electrolysis of salt and water or diluted from high concentration solutions and $\mathrm{pH}$-stabilized using caustic soda (sodium hydroxide). The MSF, CDC and WHO guidelines do not specify which chlorine source compound to use. As each source compound has drawbacks and benefits (Table 2), the responders select the most appropriate option for each context. For example, MSF now informally recommends NaDCC based on logistical and safety benefits. Additional relevant chlorine chemistry factors include $\mathrm{pH}$, as a lower $\mathrm{pH}$ is associated with a shorter chlorine solution shelf-life (defined as the time until the solution degrades by $10 \%$ ) and higher efficacy [8], and how to test chlorine solution concentration to ensure it is accurately $0.05 \%$ or $0.5 \%$. MSF guidelines recommended making solutions daily using a reliable method and not testing the concentration daily; while WHO and CDC guidelines did not address testing (Table 1). It is important to note that while high concentration powders ( $\mathrm{HTH}, \mathrm{NaDCC}$ ) are known to have longer shelf-lives than concentrated liquids $(\mathrm{NaOCl})$, we tested the shelf-lives of the dilute solutions made with those concentrated powder and liquid products in this work.

Table 2. Benefits and Drawbacks of Disinfectants Used for Surfaces and Hands.

\begin{tabular}{|c|c|c|}
\hline & Benefits & Drawbacks \\
\hline Bar soap and water & $\begin{array}{l}\text { Widely available } \\
\text { Widely acceptable } \\
\text { Low cost }\end{array}$ & $\begin{array}{c}\text { Primary goal to remove, } \\
\text { not inactivate } \\
\text { Requires water }\end{array}$ \\
\hline Alcohol Based Hand Sanitizer & $\begin{array}{l}\text { Simple to use } \\
\text { Portable }\end{array}$ & $\begin{array}{c}\text { Not widely available } \\
\text { Not widely acceptable } \\
\text { Expensive }\end{array}$ \\
\hline $\mathrm{NaDCC}(\mathrm{pH}=6)$ & $\begin{array}{l}\text { Easy to ship (powder) } \\
\text { Long shelf-life of powder } \\
\text { Does not clog pipes } \\
\text { Inexpensive }\end{array}$ & - \\
\hline $\mathrm{HTH}(\mathrm{pH}=11)$ & $\begin{array}{l}\text { Easy to ship (powder) } \\
\text { Long shelf-life of powder } \\
\text { Inexpensive }\end{array}$ & $\begin{array}{l}\text { Clogs pipes } \\
\text { Can be explosive }\end{array}$ \\
\hline Stabilized $\mathrm{NaOCl}(\mathrm{pH}=11)$ & $\begin{array}{l}\text { Can be locally produced } \\
\text { Does not clog pipes }\end{array}$ & $\begin{array}{c}\text { Shorter shelf-life of concentrate } \\
\text { Difficult to ship }\end{array}$ \\
\hline Generated $\mathrm{NaOCl}(\mathrm{pH}=9)$ & $\begin{array}{l}\text { Can be produced on-site } \\
\text { Does not clog pipes }\end{array}$ & $\begin{array}{c}\text { Shorter shelf-life of concentrate } \\
\text { Difficult to ship } \\
\text { Quality control }\end{array}$ \\
\hline
\end{tabular}

Acronyms: NaDCC (sodium dichloroisocyanurate), $\mathrm{HTH}$ (calcium hypochlorite), $\mathrm{NaOCl}$ (sodium hypochlorite).

Shelf-life: We conducted 30-day shelf life experiments with $0.05 \%$ and $0.5 \% \mathrm{NaDCC}, \mathrm{HTH}$ and stabilized $\mathrm{NaOCl}$ in addition to generating $\mathrm{NaOCl}$ solutions at $25-35^{\circ} \mathrm{C}$.

Testing Methods: Fourteen commercially available methods to test $0.5 \%$ and $0.05 \%$ solutions were identified and assessed for: accuracy and precision in the laboratory setting; ease-of-use with volunteers; and cost using available data [9]. 


\subsection{EVD Research Thread \#2: Surface Cleaning Methods}

To begin the surface cleaning work, four bacteriophages sharing characteristics with the Ebola virus were identified [10] and a surface disinfection experiment completed with the Ebola virus by Cook et al. in a Biosafety Level 4 laboratory was replicated [11,12]. After this, the testing matrix was developed that included various surface types that are relevant in emergency health responses (nitrile, heavy duty tarp, stainless steel); chlorine types ( $\mathrm{NaDCC}, \mathrm{HTH}$, generated $\mathrm{NaOCl}$, stabilized $\mathrm{NaOCl}$ ); soil load (with and without); and factors that varied between the MSF, WHO and CDC recommendations, including exposure time $(10,15 \mathrm{~min}$ ) and recommended pre-treatments (none, covering, wiping, covering/wiping) [13]. The bacteriophage that was most similar to the Ebola virus from the above study was left to dry for one hour on a disc with a surface diameter of $8 \mathrm{~cm}$, disinfection was carried out with or without pre-treatment and the residual contamination on the disc was measured at the end of the exposure time.

\subsection{EVD Research Thread \#3: Handwashing Safety and Efficacy Methods}

In the West African EVD outbreak, the recommendation to wash hands with $0.05 \%$ chlorine solution was widely extended beyond ETU settings to community settings. The MSF, CDC and WHO guidelines were inconsistent on whether it was safe (due to potential hand irritation that might increase transmission) or efficacious (due to chlorine demand of skin) to wash hands with $0.05 \%$ chlorine solution.

Safety: To assess safety, a randomized trial with 91 volunteers who washed their hands 10 times a day for 28 days was conducted [14]. Volunteers were assigned and used commercially-available bar soap and water; $70 \%$ ethanol hand sanitizer (referred herein as 'sanitizer' and equivalent "alcohol based hand sanitizer, ABHS"); or $0.05 \%$ chlorine solution created from $\mathrm{HTH}, \mathrm{NaDCC}$, generated $\mathrm{NaOCl}$ or stabilized $\mathrm{NaOCl}$ for handwashing. The outcomes included irritation as measured by the Hand Eczema Score Index (HECSI) (range 0-360), signs of transmission risk (e.g., cracking) and dermatitis diagnosis.

Efficacy: To assess the efficacy of handwashing methods, 18 volunteers' hands were spiked on four separate trial days with a non-infectious BSL-1 E. coli or the selected BSL-1 surrogate from above, with and without soil load $[15,16]$. For each trial, the volunteers completed seven handwashing methods, including control (nothing); water only; soap and water; sanitizer; and HTH, NaDCC, generated $\mathrm{NaOCl}$ and $\mathrm{pH}$-stabilized $\mathrm{NaOCl}$ solutions. After each washing, any remaining organisms were recovered from hands and rinsing water (if available) was collected and tested for remaining E. coli or selected bacteriophage.

\section{Results}

\subsection{EVD Research Thread \#1: Chlorine Chemistry}

Shelf-life: $\mathrm{NaDCC}$ solutions $(\mathrm{pH}=6)$ had a maximum shelf life of 2 days, generated $\mathrm{NaOCl}$ solutions $(\mathrm{pH}=9) 6$ days and HTH and stabilized $\mathrm{NaOCl}$ solutions $(\mathrm{pH}=11)>30$ days [17]. Extrapolating to $40^{\circ} \mathrm{C}$ using mathematical modeling, NaDCC solutions fell to a shelf-life of $<1$ day, while other chlorine source compound solutions remained with shelf-lives of 5 days $>30$ days.

Testing Method: Accuracy and precision were greatest in titration methods, followed by $\mathrm{N}, \mathrm{N}$-diethyl-p-phenylenediamine (DPD) color change dilution methods and test strips [9]. Conversely, titration was most expensive and hardest to use, while test strips were the least expensive and easiest to use. Results from most non-titration methods varied with solution $\mathrm{pH}$, with the exception of one test strip.

Summary of Research Thread \#1: Each chlorine source compound has benefits and drawbacks and it is recommended that responders choose the appropriate compound for their context, while ensuring chlorine solutions made from these source compounds are stored appropriately, used within their shelf-life, periodically tested by trained personnel using titration methods and tested daily with 
$\mathrm{pH}$-resistant test strips. For example, in a large ETU, NaDCC powder may be the most appropriate chlorine source compound as the solutions would be used within a few hours. In a small ETU making solutions once per day or a community setting where solutions are made once per week, HTH (if powder is stored appropriately to mitigate explosive risk) or $\mathrm{NaOCl}$ may be most appropriate.

\subsection{EVD Research Thread \#2: Surface Cleaning Results}

After we replicated the surface disinfection experiment completed with the Ebola virus using each of the selected bacteriophages, Phi6 appeared slightly more resistant than the Ebola virus under the tested conditions and was thus identified as the most appropriate surrogate [12].

Across the entire test matrix, there was always a reduction of $>99.9 \%$ in Phi6 [13] The results suggest that: (1) surface type influenced disinfection efficacy; (2) chlorine type and soil load did not impact disinfection efficacy when using $0.5 \%$ chlorine; (3) contact time did impact efficacy against Phi6; and (4) wiping or covering did not increase disinfection efficacy, but the latter could limit splashing.

Summary: Overall, a 15 -min exposure to $0.5 \%$ chlorine (independently of chlorine type, surface, pre-cleaning practices and organic matter) was found to reduce surface contamination by an Ebola virus surrogate to non-detectable levels. These results are consistent with recent results from small-scale studies using the Ebola virus [18].

\subsection{EVD Research Thread \#3: Handwashing Safety and Efficacy Results}

Safety: Although all groups experienced statistically significant increases in HECSI scores, these increases in irritation were not clinically relevant as the average HECSI score was only 9/360 after 28 days [14]. Subjects using sanitizer had the smallest increases, followed by higher $\mathrm{pH}$ chlorine solutions ( $\mathrm{HTH}$ and stabilized $\mathrm{NaOCl}$ ) as well as soap and water. Handwashing with soap and water was performed using bar soap intended for handwashing, following WHO-recommended handwashing guidelines. Although some individuals are especially sensitive to handwashing, these protocols were not expected to cause significant irritation in most people. The signs of irritation disrupting skin integrity, which are possibly related to higher transmission risk, were observed most frequently in subjects using soap and least frequently in those using sanitizer or HTH.

Efficacy: With E. coli, HTH performed most consistently well, with statistically significantly greater logarithmic reductions than other individual handwashing methods [16]. However, the magnitude of handwashing efficacy differences was small, suggesting that methods were similarly efficacious. With Phi6, no statistically significant differences were seen between controls and handwashing methods. One explanation for this is that mechanical action is the main removal mechanism for Phi6. Finally, chlorine-based handwashing methods resulted in statistically significantly less persistence of $E$. coli and Phi6 in rinsing water.

Summary: These safety and efficacy results indicate all handwashing methods were roughly equally efficacious in practice, although: (1) HTH in particular was consistently more safe and efficacious; and (2) chlorine solutions, as compared to soap and water and sanitizer, offer the benefit of reducing pathogen persistence in rinsing water. As all handwashing methods have benefits and drawbacks (Table 2), it is recommended that EVD responders and communities use whichever handwashing method(s) are most acceptable, available and feasible for handwashing, considering that chlorine solutions may offer a benefit in reducing transmission risk from rinsing water.

\section{Discussion}

In this work, it was found that: (1) chlorine source compound chemistry has an impact on the chlorine solution shelf-life, with solutions made from NaDCC having the shortest shelf life and solutions from $\mathrm{HTH}$ and $\mathrm{NaOCl}$ the longest; (2) testing of $0.05 \%$ and $0.5 \%$ chlorine solutions is recommended to ensure accuracy, particularly when solutions are not made continuously or daily; (3) surface cleaning with $0.5 \%$ solutions with a 15 -min exposure time is efficacious at reducing (but not eliminating) transmission risk from the very low infectious dose Ebola virus; and (4) handwashing 
with chlorine solutions is as safe and efficacious as handwashing with soap and water or sanitizer, which also offers a benefit of reducing pathogens in rinsing water. Across all studies, the chlorine source compound HTH performed particularly well, with chlorine solutions made from this product having the longest shelf-life, the least hand irritation and the highest handwashing efficacy. However, HTH has the operational challenges of being more explosive than NaDCC and having a precipitate form in mixing with water that can clog pipes. In well-maintained ETUs, this can be managed with appropriate training and maintenance. However, explosions did occur in ETUs that were managed by less experienced organizations in the West African outbreak, which poses a great risk to the health and safety of response personnel and patients (personal communication, available from authors to protect privacy). Additionally, the MSF guidelines were most often found to be both efficacious and achievable in the field, indicating that field experience provided solid guidelines in the absence of evidence and in this circumstance.

Overall, the work was successful at answering responder questions and providing information to align inconsistent international guidelines. Factors that led to this successful research included: (1) funding allocated with the knowledge that the results would most likely not be available for the current outbreak but for the next outbreak; and (2) collaborations with an interdisciplinary team, including researchers with expertise in laboratory testing and human subject trial design, clinicians and responders. One key lesson from this work is that partnering laboratories working with the Ebola virus (with small sample processing capacity) with laboratories using surrogates (with large sample processing capacity) is one mechanism to promote rapid response research in outbreaks. The main limitation of this work is that it was reactive, rather than proactive.

\section{Future Research Needed}

Between 1980 and 2013, 12,102 outbreaks of 215 human infectious diseases, including more than 44 million cases, were reported from 219 nations [19]. This statistic is substantial even when taking into account the improved capabilities to recognize and diagnosis outbreaks that occurred during this time. Although outbreaks are defined as an increase in the number of cases beyond expectations, human EIDs are further characterized by novelty. Diseases that have undergone recent evolutionary change, have been newly recognized or re-emerging, have entered the human population for the first time, have bioterrorism potential or are newly-developed antibiotic resistance are classified as EIDs.

EID introductions have risen significantly over time and these introductions are mostly zoonotic in nature [20]. The factors that have led to increases in EID introductions include environmental, social, political and economic changes [21,22]. Although the transmission pathways differ for the EID pathogens vary, many of these pathways can be interrupted and their transmission prevented by appropriate disinfection interventions. However, there is currently a knowledge gap on disinfection efficacy and safety for these EID pathogens, especially in low-resource settings. Research is needed to proactively (rather than retroactively) establish the efficacy, safety and suitability of cleaning, disinfection and sterilization practices. The research should systematically include the pathogen of interest and relevant surrogates (ensuring that the surrogates are representative of the pathogen by completing low-volume sampling of the pathogen and high-volume sampling of the surrogate), hands and surfaces and materials used in high and low-resource health facilities and communities, cleaning procedures, appropriate disinfectants and sterilizers and matrices that are representative of bodily fluids (blood, vomit, feces). Additionally, the research should include factors that are known to affect disinfection efficacy on viruses, including the presence or absence of an envelope, aggregation and relative humidity $[23,24]$. Finally, the capacity to rapidly conduct research in the event of a novel EID outbreak is needed and developing appropriate surrogates could help improve research responsiveness/capacity.

To facilitate this research, partnerships between responders, donors and researchers are necessary. Responders can voice questions and share field experience; researchers can design and conduct high-quality studies (including prioritizing timely, open-access publication); and donors can prioritize 
funding this research before an outbreak or at the onset of an outbreak. The overall goal of this type of collaborative research is to advance the understanding of the efficacy, safety and suitability of disinfectants to reduce EID transmission, keep healthcare providers and community members safe and increase EID outbreak emergency preparedness.

Author Contributions: D.L., M.W. and K.G. conceived and designed the experiments described in this research; the experiments, data analysis and publication of data referenced in this manuscript were all led by D. L., M.W., K.G. and D. L.; with K.G., M.W. and M.O., reviewing and providing comments. M.O. represents the main funder of the study.

Funding: This research was funded by United States Agency for International Development's Office of U.S. Foreign Disaster Assistance (USAID/OFDA).

Acknowledgments: We would like to thank all our co-authors and collaborators and supporters named in each of the individual manuscripts referenced herein.

Conflicts of Interest: The authors declare no conflict of interest. The funder had no role in the collection, analyses, or interpretation of data or in the decision to publish the results herein or in the manuscripts referenced herein. However, the funder did have a role in approving the design of all the individual research threads referenced herein and in the writing of this summary manuscript.

\section{References}

1. Mehtar, S.; Bulabula, A.; Nyandemoh, H.; Jambawai, S. Deliberate exposure of humans to chlorine-The aftermath of Ebola in West Africa. Antimicrob. Resist. Infect. Control 2016, 5, 45. [CrossRef] [PubMed]

2. Centers for Disease Control and Prevention. A CDC Framework for Preventing Infectious Diseases: Sustaining the Essentials and Innovating for the Future; Centers for Disease Control and Prevention: Atlanta, GA, USA, 2011.

3. Rutala, W.A.; Weber, D.J. Healthcare Infection Control Practices Advisory Committee. Guideline for Disinfection and Sterilization in Healthcare Facilities; Centers for Disease Control and Prevention: Atlanta, GA, USA, 2008.

4. World Health Organization. Who Publishes List of Top Emerging Diseases Likely to Cause Major Epidemics; World Health Organization: Geneva, Switzerland, 2016.

5. Médecins Sans Frontières. Filovirus Haemorrhagic Fever Guideline; Médecins Sans Frontières: Barcelona, Spain, 2008.

6. World Health Organization. Ebola Virus Disease (EVD): Key Questions and Answers Concerning Water, Sanitation and Hygiene; World Health Organization: Geneva, Switzerland, 2016.

7. Centers for Disease Control and Prevention. For General Healthcare Settings in West Africa: Rationale and Considerations for Chlorine Use in Infection Control; Centers for Disease Control and Prevention: Atlanta, GA, USA, 2016.

8. Lantagne, D.; Preston, K.; Blanton, E.; Kotlarz, N.; Gezagehn, H.; van Dusen, E.; Berens, J.; Jellison, K. Hypochlorite solution expiry and stability in household water treatment in developing countries. J. Environ. Eng. 2011, 137, 131-136. [CrossRef]

9. Wells, E.; Wolfe, M.K.; Murray, A.; Lantagne, D. Accuracy, precision, ease-of-use and cost of methods to test ebola-relevant chlorine Solutions. PLoS ONE 2016, 11, e0152442. [CrossRef] [PubMed]

10. Mesquita, M.M.; Stimson, J.; Chae, G.T.; Tufenkji, N.; Ptacek, C.J.; Blowes, D.W.; Emelko, M.B. Optimal preparation and purification of prd1-like bacteriophages for use in environmental fate and transport studies. Water Res. 2010, 44, 1114-1125. [CrossRef] [PubMed]

11. Cook, B.W.; Cutts, T.A.; Nikiforuk, A.M.; Poliquin, P.G.; Court, D.A.; Strong, J.E.; Theriault, S.S. Evaluating environmental persistence and disinfection of the Ebola virus Makona variant. Viruses 2015, 7, 1975-1986. [CrossRef] [PubMed]

12. Gallandat, K.; Lantagne, D. Selection of a biosafety level 1 (BSL-1) surrogate to evaluate surface disinfection efficacy in Ebola outbreaks: Comparison of four bacteriophages. PLoS ONE 2017, 12, e0177943. [CrossRef] [PubMed]

13. Gallandat, K.; Wolfe, M.K.; Lantagne, D. Surface cleaning and disinfection: Efficacy assessment of four chlorine types using Escherichia coli and the Ebola surrogate Phi6. Environ. Sci. Technol. 2017, 51, 4624-4631. [CrossRef] [PubMed] 
14. Wolfe, M.K.; Wells, E.; Mitro, B.; Desmarais, A.M.; Scheinman, P.; Lantagne, D. Seeking clearer recommendations for hand hygiene in communities facing Ebola: A randomized trial investigating the impact of six handwashing methods on skin irritation and dermatitis. PLOS ONE 2016, 11, e0167378. [CrossRef] [PubMed]

15. Wolfe, M.K.; Lantagne, D.S. A method to test the efficacy of handwashing for the removal of emerging infectious pathogens. J. Vis. Exp. 2017, 124, e55604. [CrossRef] [PubMed]

16. Wolfe, M.K.; Gallandat, K.; Daniels, K.; Desmarais, A.M.; Scheinman, P.; Lantagne, D. Handwashing and Ebola virus disease outbreaks: A randomized comparison of soap, hand sanitizer and $0.05 \%$ chlorine solutions on the inactivation and removal of model organisms phi6 and E. coli from hands and persistence in rinsing water. PLoS ONE 2017, 12, e0172734. [CrossRef] [PubMed]

17. Iqbal, Q.; Lubeck-Schricker, M.; Wells, E.; Wolfe, M.K.; Lantagne, D. Shelf-life of chlorine solutions recommended in Ebola virus disease response. PLoS ONE 2016, 11, e0156136. [CrossRef] [PubMed]

18. Cook, B.W.; Cutts, T.A.; Nikiforuk, A.M.; Leung, A.; Kobasa, D.; Theriault, S.S. The disinfection characteristics of Ebola virus outbreak variants. Sci. Rep. 2016, 6, 38293. [CrossRef] [PubMed]

19. Smith, K.F.; Goldberg, M.; Rosenthal, S.; Carlson, L.; Chen, J.; Chen, C.; Ramachandran, S. Global rise in human infectious disease outbreaks. J. R. Soc. Interface 2014, 11, 20140950. [CrossRef] [PubMed]

20. Jones, K.E.; Patel, N.G.; Levy, M.A.; Storeygard, A.; Balk, D.; Gittleman, J.L.; Daszak, P. Global trends in emerging infectious diseases. Nature 2008, 451, 990-993. [CrossRef] [PubMed]

21. Morse, S.S. Factors and determinants of disease emergence. Rev. Sci. Tech. 2004, 23, 443-451. [CrossRef] [PubMed]

22. Morse, S.S. Factors in the emergence of infectious diseases. Emerg. Infect. Dis. 1995, 1, 7-15. [CrossRef] [PubMed]

23. Wigginton, K.R.; Pecson, B.M.; Sigstam, T.; Bosshard, F.; Kohn, T. Virus inactivation mechanisms: Impact of disinfectants on virus function and structural integrity. Environ. Sci. Technol. 2012, 46, 12069-12078. [CrossRef] [PubMed]

24. Ye, Y.; Chang, P.H.; Hartert, J.; Wigginton, K.R. Reactivity of enveloped virus genome, proteins and lipids with free chlorine and $\mathrm{UV}_{254}$. Environ. Sci. Technol. 2018, 52, 7698-7708. [CrossRef] [PubMed] 